\title{
Husband Support Rises Women's Awareness of Preconception Care in Northern Ethiopia
}

\author{
Mulugeta Woldu Abrha (D), ${ }^{1}$ Tsrity Tadese Asresu, ${ }^{2}$ \\ and Haftom Gebrehiwot Weldearegay (D) $^{3}$ \\ ${ }^{1}$ Tigray Health Research Institute, Mekelle, Ethiopia \\ ${ }^{2}$ Mekelle University, College of Health Sciences, Mekelle, Ethiopia \\ ${ }^{3}$ Mekelle University, College of Health Sciences, Department of Midwifery, Mekelle, Ethiopia \\ Correspondence should be addressed to Mulugeta Woldu Abrha; mulugetawoldu425@gmail.com
}

Received 2 October 2019; Accepted 23 December 2019; Published 22 January 2020

Academic Editor: Enzo Berardesca

Copyright (C) 2020 Mulugeta Woldu Abrha et al. This is an open access article distributed under the Creative Commons Attribution License, which permits unrestricted use, distribution, and reproduction in any medium, provided the original work is properly cited.

\begin{abstract}
Background. Preconception care (PCC) aims to improve pregnancy and health outcomes of mothers and their offspring. However, there is no adequate evidence of awareness on preconception care in Ethiopia. Therefore, the present study was performed to assess the level of awareness and associated factors of preconception care among currently delivered mothers. Method. A community-based cross-sectional study was conducted among 561 mothers in Northern Ethiopia. Data were collected using a pretested, structured questionnaire. Odds ratio presented with $95 \%$ confidence interval, and a $p$ value $<0.25$ at bivariable and $p$ value $<0.01$ at multivariable logistic regression were used to declare statistical significance. Results. 39.0\% of mothers were aware of preconception care. Awareness of preconception care was lower among mothers who did not have joint plan discussion with their partner $(\mathrm{AOR}=0.15 ; 95 \% \mathrm{CI}(0.08,0.28))$; did not have a history of adverse pregnancy outcome $(\mathrm{AOR}=0.45 ; 95 \% \mathrm{CI}(0.25,0.83))$, and did not receive husband support $(\mathrm{AOR}=0.10 ; 95 \% \mathrm{CI}(0.05,0.19))$. Conclusion. Women's awareness of preconception care remains low. Joint plan discussion with the partner, previous history of adverse pregnancy outcome, and husband support were statistically significant predictors of awareness of preconception care. Thus, informing and sensitizing women and advocating husband support on preconception care are needed.
\end{abstract}

\section{Introduction}

Today, preconception care (PCC) is internationally recognized, and obstetric care should increasingly focus on prevention of adverse pregnancy outcomes [1]. The preconception period provides an opportunity to alter unhealthy behaviors in time, which could have a lasting positive effect on the (future) health outcomes of both the mother and child [2].

Globally, PCC is widely recognized as a way to optimize women's health and improve pregnancy outcomes [3]. Although there is a growing body of evidence supporting that prepregnancy is a critical period for both maternal and fetal health, preconception care is inconsistent and has not become part of routine practice in all settings. The practice of preconception care is almost nonexistent in developing countries including Ethiopia [4].

Furthermore, preconception care is a neglected but a critical component of maternal and a child health care service as it is a cost-effective first-line preventive strategy for birth defects and other pregnancy-related complications. The early years of a child's life are critical in shaping future health and wider outcomes. National policy now supports a shift in focus to prevention and early intervention in the earliest years, from prebirth onwards. The early year's framework sets out the need for change from crisis management to prevention, early identification of need, and early intervention through progressive universalism. It highlights the value of healthy pregnancies, positive parenting, and home-learning environments [3,5-7]. 
Thus, in settings like Ethiopia, where there are imprecise data on awareness of preconception care, promotion of preconception care among the reproductive age group women is important to boost maternal health-care services and to reduce pregnancy-related impediments. Therefore, this study sought to determine the level of women's awareness and associated factors of preconception-care service in Northern Ethiopia. So, the findings will contribute to the design of effective preventive strategies to grab the rising burden of adverse pregnancy and birth outcomes and flourish programs for better reproductive health services.

\section{Materials and Methods}

2.1. Study Design, Setting, and Participants. A communitybased cross-sectional study was conducted in Mekelle City, which is the capital city of Tigray Regional state, Northern Ethiopia, from March 15 to April 30, 2018.

The source of population was all delivered mothers preceding the study in Mekelle City and all recently delivered mothers in selected ketenas of Mekelle city were the study population.

2.2. Sampling Technique and Procedure. The sample size was calculated using a single population formula assuming proportion $(\mathrm{P})$ of preconception care experience of $38.2 \%$ conducted at West Shewa, Oromia, Ethiopia [8], a confidence level (CI) of 95\%, marginal error (d) 5\% and 5\% nonresponse, and considering a design effect of 1.5. Considering all the aforementioned assumptions, the abovementioned 564 mothers were included. A multistage cluster sampling technique was employed; in the first stage, three from seven subcities and in the second stage, five tabia (the unit of administration consists of 3 and above or $10-15,000$ population) from fourteen tabias (the unit of administration consists of 3 and above or $10-15,000$ population) of the selected subcities were randomly selected, and then each two of their respective ketenas (the smallest unit of administration consists of a minimum of 4,000 population, but sometimes depends on the geographical location.) according to the currently used administration were selected again by a simple random sampling technique (SRS).

\subsection{Data Collection Instrument and Quality Management.} The data were collected using a face-to-face interview. Prior to data collection, reliability test of the instrument was performed, and it had strong internal consistency $(\alpha=0.76)$ among a subsample of participants $(n=30)$. Daily supervision, spot checking, and reviewing the completeness of the questionnaire were conducted to keep the quality of data.

2.4. Statistical Analyses. Data were coded and entered into EPi-Info version 7 software. Descriptive analysis was performed. Age was reported as mean \pm Standard Deviation (SD), after the Kolmogorov-Smirnov goodness-of-fit test was applied for determining whether the data derived from a normally distributed population. Binary logistic regression and multivariable logistic regression models were used to obtain crude and adjusted odds ratios for the outcome variable, using the SPSS $20^{\mathrm{TM}}$-statistical package. The statistical significance was set at $p<0.01$.

2.5. Ethical Consideration. Ethical clearance was obtained from Mekelle University, college of health sciences; Ethical Review Board. An official letter of cooperation was granted by the Tigray Regional Health Bureau, and written informed consent was warranted from all participants.

\section{Results}

3.1. Sociodemographic Characteristics. Out of the total five hundred and sixty-four mothers who delivered within the last one year, 561 were included in the study. Of the 561 participants, 277 (49.4\%) were within the age group between 25 and 34 years and ranged from a minimum of 18 years to a maximum of 43 years. The mean age of the respondents was 31.22 years $(\mathrm{SD}=6.04)$.

Four out of ten mothers were housewives, and threefourth of the participants were married. Regarding participants' education, 191 (34\%) were from secondary school (Table 1).

3.2. Reproductive Health Characteristics. About two-third of the participants had experienced two to four pregnancies. Concerning parity, three-fourth $(n=423)$ of the participants were multipara. Three hundred and forty-one out of 561 respondents had a history of family planning use. On the subject of previous adverse pregnancy or birth outcome, two out of ten, $118(21 \%)$, of them had a history of adverse pregnancy/birth outcome. Thirty-nine $(7.0 \%)$ of the respondents had a chronic health problem. Regarding husband support on the preconception care, only 159 (28.3\%) of the participants had received husband support during the preconception period and 167 (29.8\%) of the subjects have had a joint plan discussion with their partner about preconception care (Table 2).

3.3. Awareness of Preconception Care. Two hundred and nineteen $(39.0 \%)$ of the participants were aware of preconception care (Figure 1). According to the source of information, majority of the mothers have heard about PCC from physicians, 103 (47.0\%), and twenty-seven (12.3\%) of them have heard from health extension workers. Six out of ten mothers were aware of the difference between antenatal care and preconception care services. Moreover, about twothirds, $153(69.7 \%)$, of mothers were aware of the time a women should start the uptake of preconception care (Table 3).

Furthermore, from the WHO preconception care package components, about three-fourth, 168 (76.7\%), of the mothers were aware of screening and treatment of infectious disease, whereas one out of ten, 30 (13.7\%), were aware of optimizing psychological health (Figure 2). 
TABle 1: Sociodemographic characteristics of mothers in North Ethiopia, $2018(N=561)$.

\begin{tabular}{lcc}
\hline Variable & Frequency & Percent (\%) \\
\hline Age & & \\
15-24 & 88 & 15.7 \\
$25-34$ & 277 & 49.4 \\
35-49 & 196 & 34.9 \\
Mother's education & & \\
Illiterate & 74 & 13.2 \\
Read and write & 73 & 13.0 \\
Elementary school & 127 & 22.6 \\
Secondary school & 191 & 34.0 \\
College/university & 96 & 17.1 \\
Marital status & & \\
Married & 438 & 78.1 \\
Single/never married & 62 & 11.1 \\
Divorced & 53 & 9.4 \\
Widowed & 8 & 1.4 \\
Occupation & & \\
House wife & 232 & 41.4 \\
Daily worker & 94 & 16.8 \\
Government employee & 104 & 18.5 \\
Private business & 129 & 23.0 \\
Other (student) & 2 & 0.4 \\
Household income in ETB & & 23.5 \\
Less than 500 & 132 & 36.9 \\
501-1000 & 207 & 12.7 \\
1001-2000 & 151 & \\
2001 and above & 71 & \\
\hline
\end{tabular}

3.4. Factors Associated with Awareness of Preconception Care Service. In bivariable analysis, maternal age, educational status, occupation, household income, history of family planning use, experience of adverse pregnancy or birth outcome, joint plan discussion with their partner, and husband support were associated with awareness of preconception care. Finally, multivariable analysis showed that experience of adverse pregnancy or birth outcome, joint plan discussion with their partner, and husband support were independently affecting maternal awareness of preconception care service.

Mothers who had not experienced adverse birth outcomes were $55 \%$ times $(\mathrm{AOR}=0.45 ; 95 \% \mathrm{CI}(0.25,0.83))$ less likely to be aware of preconception care service than mothers who had had a history of adverse pregnancy or birth outcome.

There were lower odds $(\mathrm{AOR}=0.15 ; 95 \% \mathrm{CI}(0.08,0.28)$ ) of preconception care service awareness among mothers who have not had joint plan discussion with their partner as compared with mothers who had had joint plan discussion with their partner.

Furthermore, this study revealed that experience of husband support has a significant association on awareness of preconception care, which means mothers who had not received husband support were $90 \%$ times ( $\mathrm{AOR}=0.10 ; 95 \%$ CI $(0.05,0.19))$ less likely to be aware of preconception care service as compared with mothers who had received support from their husbands (Table 4).
TABLE 2: Reproductive health characteristics of mothers in North Ethiopia, $2018(N=561)$.

\begin{tabular}{|c|c|c|}
\hline Variable & Frequency & Percent \\
\hline \multicolumn{3}{|l|}{ Gravidity } \\
\hline 1 pregnancy & 113 & 20.1 \\
\hline $2-4$ pregnancies & 379 & 67.6 \\
\hline$\geq 5$ pregnancies & 69 & 12.3 \\
\hline \multicolumn{3}{|l|}{ Parity } \\
\hline Primipara (1 pregnancy) & 138 & 24.6 \\
\hline Multipara ( 2 and above pregnancies) & 423 & 75.4 \\
\hline \multicolumn{3}{|l|}{ Previous use of family planning } \\
\hline Yes & 341 & 60.8 \\
\hline No & 220 & 39.2 \\
\hline \multicolumn{3}{|l|}{ Previous adverse pregnancy/birth outcome } \\
\hline Yes & 118 & 21.0 \\
\hline No & 443 & 79.0 \\
\hline \multicolumn{3}{|l|}{$\begin{array}{l}\text { Type of adverse pregnancy outcome } \\
(n=118)\end{array}$} \\
\hline Congenital anomalies & 23 & 19.5 \\
\hline Low birth weight & 17 & 14.4 \\
\hline Preterm & 10 & 8.5 \\
\hline Abortion & 67 & 56.8 \\
\hline Still birth & 22 & 18.6 \\
\hline Neonatal death & 7 & 5.9 \\
\hline Infection & 13 & 11.0 \\
\hline \multicolumn{3}{|l|}{ Husband support } \\
\hline Yes & 159 & 28.3 \\
\hline No & 402 & 71.7 \\
\hline \multicolumn{3}{|l|}{ Joint plan discussion with partner } \\
\hline Yes & 167 & 29.8 \\
\hline No & 394 & 70.2 \\
\hline \multicolumn{3}{|l|}{ Any chronic health problem } \\
\hline Yes & 39 & 7.0 \\
\hline No & 522 & 93.0 \\
\hline \multicolumn{3}{|l|}{ Type of chronic health problem $(n=39)$} \\
\hline HIV/AIDS & 14 & 35.9 \\
\hline Hypertension & 14 & 35.9 \\
\hline Diabetics mellitus & 5 & 12.8 \\
\hline Others* & 8 & 20.5 \\
\hline
\end{tabular}

*Epilepsy, tuberculosis, and anemia.

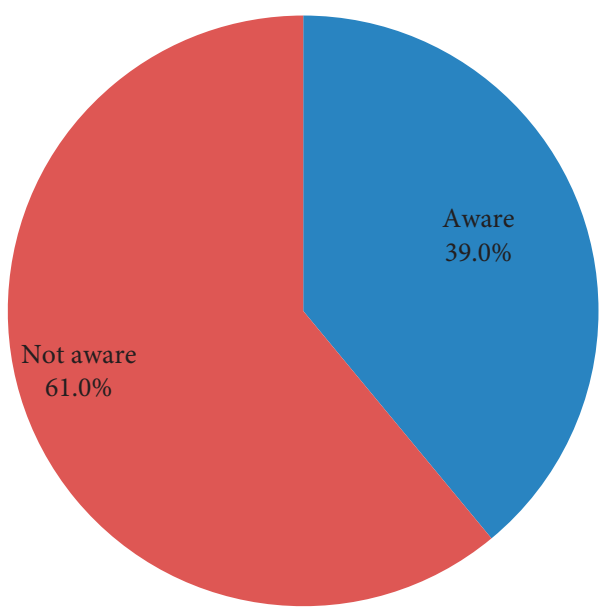

Figure 1: Awareness of mothers on preconception care in Mekelle, North Ethiopia, 2018. 
TABLe 3: Awareness on preconception care among mothers in North Ethiopia, $2018(N=561)$.

\begin{tabular}{|c|c|c|}
\hline Variables & Frequency & Percent \\
\hline \multicolumn{3}{|l|}{ Source of information $(n=219)$} \\
\hline Physician & 103 & 47.0 \\
\hline Nurse/midwife & 81 & 37.0 \\
\hline Health extension worker & 27 & 12.3 \\
\hline Peer/family & 30 & 13.7 \\
\hline Mass media & 62 & 28.3 \\
\hline \multicolumn{3}{|c|}{ Awareness regarding the difference between ANC and PCC $(n=219)$} \\
\hline Yes & 137 & 62.6 \\
\hline No & 82 & 37.4 \\
\hline \multicolumn{3}{|c|}{ Awareness of the time a women should start the uptake of preconception care $(n=219)$} \\
\hline At least one month before conception & 153 & 69.7 \\
\hline During pregnancy & 21 & 9.6 \\
\hline During labor & 15 & 6.8 \\
\hline Do not know & 30 & 13.7 \\
\hline
\end{tabular}

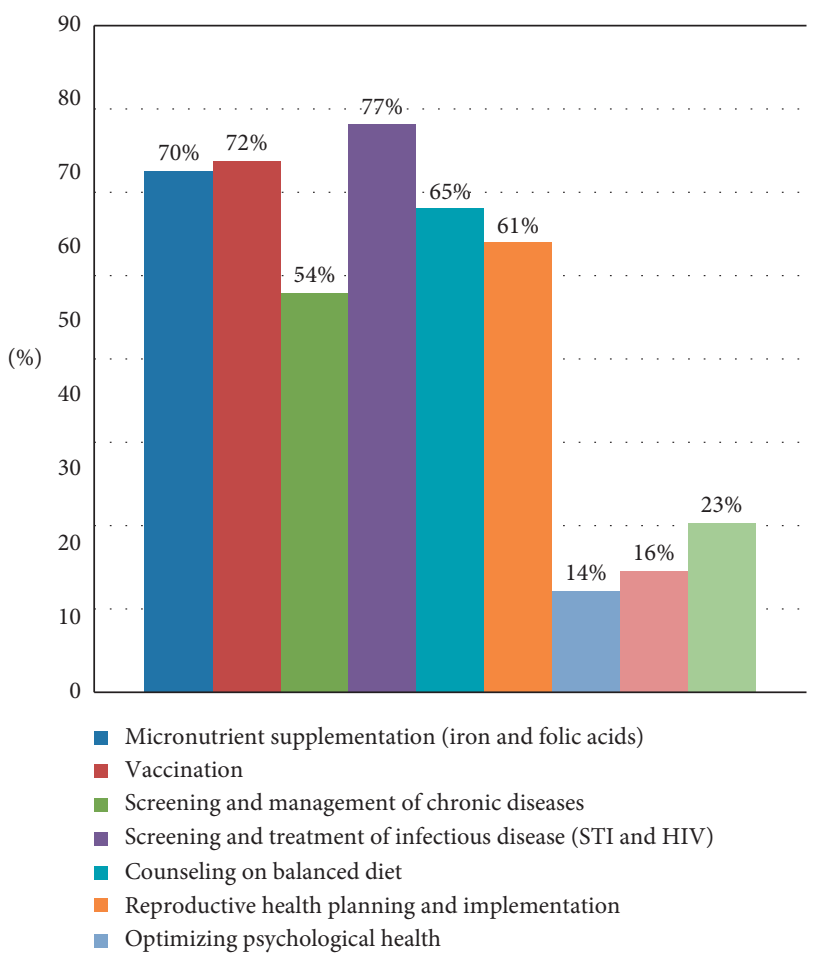

FIGURE 2: Level of awareness of mothers on the World Health Organization components of preconception care, 2018.

\section{Discussion}

Disseminating information concerning the services given during conception care will improve the maternal and child health in general, leading to positive reproductive outcome. PCC describes education that targets the preconception and early pregnancy periods and addresses optimizing current health status and relevant lifestyle behaviors. Therefore, this community-based cross-sectional study revealed that previous adverse pregnancy or birth outcome, having joint plan discussion with the partner, and husband support were the identified factors influencing awareness of preconception care among mothers who gave birth during the last one year in Mekelle town, North Ethiopia.
This study revealed that there was low awareness level of respondents regarding preconception care. This is lower than the findings conducted in Jordan 50\% [9] and Nigeria which revealed that $63.5 \%$ women had been aware of preconception care [10]. The possible reason for this discrepancy might be due to access of information, communication, and socioeconomic status difference which showed that there is a need to health education and promotion strategy to raise the low level of awareness in our setting. The main source of information of preconception care in this study were the health-care providers, mainly physicians, $47.0 \%$, and this was in line with a survey carried out in Ontario where $78.4 \%$ claimed to deliver preconception care awareness by family physicians [11]. Fulfilling the right to health requires health systems to become fully responsive to women and girls, offering higher quality and more comprehensive and readily accessible services. Societies at large must end practices that critically endanger women's health and well-being among them and all forms of gender-based violence. Sustainable Development Goal (SDG) number three puts a target to reduce the global maternal mortality ratio to less than 70 per 100,000 live births and newborn mortality at least as low as 12 per 1000 live births by the year 2030 [12]. Preconception care has a positive impact on reduction in mortality and decreases the risk of adverse health effects for the woman, fetus and neonates by optimizing the woman's health and knowledge before planning and conceiving a pregnancy [13].

The study also revealed that husband support is a significant predictor of preconception care awareness. This is in line with a study done in Bayelsa state, Nigeria, which showed that mothers who had received husband support are more likely to be aware of preconception care. In other words, mothers who had not received husband support were less likely to be aware of preconception care as compared with subjects who received support from their husbands [14]. However, most women kept their pregnancy intent private between their partner and themselves and rarely sought support from family and friends during the preconception period in developing countries [15]. 
TABLE 4: Factors of women's awareness on preconception care.

\begin{tabular}{|c|c|c|c|c|}
\hline \multirow{2}{*}{ Variable } & \multicolumn{2}{|c|}{ Awareness on preconception care } & \multicolumn{2}{|c|}{ Odds ratio and $95 \% \mathrm{CI}$} \\
\hline & Aware (\%) & Not aware (\%) & Crude & Adjusted \\
\hline \multicolumn{5}{|l|}{ Age (in years) } \\
\hline $15-24$ & $45(100.0 \%)$ & $43(48.9 \%)$ & $3.14(1.84-5.33)^{*}$ & \\
\hline $25-34$ & $125(45.1 \%)$ & $152(54.9 \%)$ & $2.47(1.65-3.68)^{*}$ & \\
\hline $35-49$ & $49(25.0 \%)$ & $147(75.0 \%)$ & 1 & NS \\
\hline \multicolumn{5}{|l|}{ Mother's education } \\
\hline No education & $39(26.5 \%)$ & $108(73.5 \%)$ & $0.23(0.13-0.39)$ & \\
\hline Primary education & $47(37.0 \%)$ & $80(63.0 \%)$ & $0.37(0.21-0.64)$ & \\
\hline Secondary education & $74(38.4 \%)$ & $117(61.3 \%)$ & $0.40(0.24-0.66)$ & \\
\hline More than secondary & $59(61.5 \%)$ & $37(38.5 \%)$ & 1 & NS \\
\hline \multicolumn{5}{|l|}{ Household income in ETB } \\
\hline$<500$ & $62(47.0 \%)$ & $70(53.0 \%)$ & $0.49(0.46-1.45)$ & \\
\hline $501-1000$ & $62(30.0 \%)$ & $145(70.0 \%)$ & $0.39(0.23-0.68)^{*}$ & \\
\hline $1001-2000$ & $58(38.4 \%)$ & $93(61.6 \%)$ & $0.57(0.32-1.01)$ & \\
\hline$\geq 2001$ & $37(52.1 \%)$ & $34(47.95 \%)$ & 1 & NS \\
\hline \multicolumn{5}{|l|}{ Parity } \\
\hline Primipara (1 pregnancy) & $52(37.7 \%)$ & $86(62.3)$ & $0.93(0.62-1.38)$ & \\
\hline Multipara ( 2 and above) & $167(39.5 \%)$ & $256(60.5 \%)$ & 1 & NS \\
\hline \multicolumn{5}{|l|}{ Gravidity } \\
\hline One pregnancy & $43(38.1 \%)$ & $70(61.9 \%)$ & $1.51(0.79-2.87)$ & \\
\hline $2-4$ pregnancies & $156(41.2 \%)$ & $223(58.5 \%)$ & $1.71(0.98-2.99)$ & \\
\hline 5 and above pregnancies & $20(29 \%)$ & $49(71 \%)$ & 1 & NS \\
\hline \multicolumn{5}{|l|}{ Previous family planning use } \\
\hline No & $65(29.5 \%)$ & $155(70.5 \%)$ & $0.51(0.36-0.73)^{*}$ & \\
\hline Yes & $154(45.2 \%)$ & $187(54.8 \%)$ & 1 & NS \\
\hline \multicolumn{5}{|c|}{ Previous adverse pregnancy outcome } \\
\hline No & $284(64.1 \%)$ & $159(35.9 \%)$ & $0.54(0.36-0.82)^{*}$ & $0.45(0.25-0.83)^{* *}$ \\
\hline Yes & $58(49.2 \%)$ & $60(50.8 \%)$ & 1 & 1 \\
\hline \multicolumn{5}{|c|}{ Having joint plan discussion with partner } \\
\hline No & $79(20.1 \%)$ & $315(79.9 \%)$ & $0.05(0.03-0.08)^{*}$ & $0.15(0.08-0.28)^{* *}$ \\
\hline Yes & $140(83.8 \%)$ & $27(16.2 \%)$ & 1 & 1 \\
\hline \multicolumn{5}{|l|}{ Husband support } \\
\hline No & $82(20.4 \%)$ & $320(79.6 \%)$ & $0.04(0.03-0.07)^{*}$ & $0.10(0.05-0.19)^{* *}$ \\
\hline Yes & $137(86.2 \%)$ & $22(13.8 \%)$ & 1 & 1 \\
\hline \multicolumn{5}{|l|}{ Having any chronic diseases } \\
\hline No & $191(36.6 \%)$ & $331(63.4 \%)$ & $0.23(0.11-0.47)$ & \\
\hline Yes & $28(71.8 \%)$ & $11(28.2 \%)$ & 1 & NS \\
\hline
\end{tabular}

${ }^{*} p$ value; ${ }^{*} p$ value $<0.05 ;{ }^{* *} p$ value $<0.001$, NS: nonsignificant.

Another finding was that adverse pregnancy or birth outcome of the mother also has a significant positive association with the awareness of preconception care. This study corroborates the finding of a study conducted in Los Angeles, which indicated that a previous adverse infant outcome was associated with an increased odds of awareness and uptake of preconception care in the most recent pregnancy. This might be due to the fact that those mothers who had an experience of adverse pregnancy outcome or complication in their life were more concerned about the health status of their next pregnancy and getting a chance to consult health-care providers than those who have not had complications [16]. If a woman has appropriate awareness of preconception health and care, she can seek or easily attend the preconception care service. This can help her easily identify and effectively control the underlying risk condition that leads to abnormal birth outcome. Health-care providers participated in one research which reported poor awareness or knowledge of preconception health and care as a barrier to the uptake and delivery of preconception care [17]. Also, another study indicates that preterm birth during delivery was significantly lower among women who received preconception care compared with those who did not [18]. Hence, intervention should preferentially be conducted during the preconception period, and efforts should be made to recognize potentially treatable causes early to reduce the risk of adverse birth outcomes.

Finally, this study noted that mothers who have not had joint plan discussion with their partners were 90\% times less likely to be aware of the preconception care when compared with their counter parts. This study agrees with the guideline of Centers for Disease Control and Prevention and the U.S. Department of Health and $\mathrm{Hu}-$ man Services indicating that a woman's reproductive plan should be discussed with her own partner [19] and study conducted in Ethiopia [20] and Brazil [21]. This is because all women/couples have a reproductive life plan (e.g., whether or when they wish to have children and how they 
will maintain their reproductive health) and are influenced by interests of one to each other to reduce the occurrences of unplanned pregnancy and pregnancy-related complications. In addition, reproductive age women who planned their pregnancy are expected to know their healthiness correlated to maternal health care and may thus also have a better awareness of issues correlated to preconception care.

\section{Conclusion}

Findings of this research indicated that women's level of awareness on preconception care remains low. Joint plan discussion with the partner, previous experience of adverse pregnancy or birth outcome, and husband support were statistically significant factors of awareness of preconception care. Thus, this finding suggests that there is a need to informing and sensitizing women of reproductive age and advocating husband's support on preconception care to raise the level of awareness. There is a need for policymakers in health ministries in Ethiopia as well as relevant stakeholders to advocate for incorporation of preventive medical clinics comprising risk assessment, risk prevention, or modification for couples in general in the existing health-care delivery system.

\section{Data Availability}

The datasets used and/or analyzed during the current study are available from the corresponding author upon request.

\section{Ethical Approval}

The study was approved by Mekelle University Institutional Review Board (ERC1305/2018).

\section{Consent}

Written informed consent was obtained from each study participant.

\section{Disclosure}

The funder had no role in study design, data collection, analysis and interpretation, decision to publish, or preparation of the manuscript.

\section{Conflicts of Interest}

The authors declare that they have no conflicts of interest.

\section{Authors' Contributions}

MWA was responsible for the methodology, review, and editing the manuscript. HGW was involved in formal analysis, writing the review, and editing. TTA was involved in conceptualization and writing the original draft. All authors have read and approved the manuscript.

\section{Acknowledgments}

The authors would like to thank Mekelle University college of health science and Mekelle City. They also truthfully thank the study participants for their participation and the data collectors and supervisors for their unconditional effort to realize this study. Graduate research grant was provided by Mekelle University.

\section{References}

[1] G. D. Shannon, C. Alberg, L. Nacul, and N. Pashayan, "Preconception healthcare delivery at a population level: construction of public health models of preconception care," Maternal and Child Health Journal, vol. 18, no. 6, pp. 15121531, 2014.

[2] J. Shawe, I. Delbaere, M. Ekstrand et al., "Preconception care policy, guidelines, recommendations and services across six European countries: Belgium (Flanders), Denmark, Italy, The Netherlands, Sweden and the United Kingdom," The European Journal of Contraception \& Reproductive Health Care, vol. 20, no. 2, pp. 77-87, 2015.

[3] WHO, Policy Brief: Preconception Health; Maximizing the Gains of Maternal and Child Health, WHO, Geneva, Switzerland, 2013.

[4] Centers for Disease Control and Prevention (CDC), "Smoking prevalence among women of reproductive age-United States," Morbidity and Mortality Weekly Report, vol. 57, no. 31, pp. 849-852, 2011.

[5] K. Y. M. Ahmed, I. M. H. Elbashir, S. M. I. Mohamed, A. K. M. Saeed, and A. A. M. Alawad, "Knowledge, attitude and practice of preconception care among Sudanese women in reproductive age about rheumatic heart disease," International Journal of Public Health Research, vol. 3, no. 5, pp. 223-227, 2015.

[6] A. Steel, J. Lucke, and J. Adams, "The prevalence and nature of the use of preconception services by women with chronic health conditions: an integrative review," BMC Women's Health, vol. 15, no. 1, p. 14, 2015.

[7] D. Mazza and A. Chapman, "Improving the uptake of preconception care and periconceptional folate supplementation: what do women think?," BMC Public Health, vol. 10, no. 1, pp. 1-6, 2010.

[8] A. Gezahegn, Assessment of Knowledge and Experiance of Preconception Care Among Pregnant Mothers Attending ANC in West Shoa Zone, Public Health Centers, Ethiopia, AAU, College of Health Sciences School of Allied Health Sciences, Department of Midwifery and Nursing, Addis Ababa, Ethiopia, 2016.

[9] N. A. Al-Akour, R. Sou'Ub, K. Mohammad, and F. Zayed, "Awareness of preconception care among women and men: a study from Jordan," Journal of Obstetrics and Gynaecology, vol. 35, no. 3, pp. 246-250, 2015.

[10] A. E. Olowokere, A. Komolafe, and C. Owofadeju, "Awareness, knowledge and uptake of preconception care among women in ife central local government area of Osun State, Nigeria," Journal of Community Medicine and Primary Health Care, vol. 27, no. 2, pp. 83-92, 2015.

[11] Best Start Resource Centre, Preconception Health: Awareness and Behaviors in Ontario, Best Start Resource Centre, Toronto, ON, Canada, 2009.

[12] World Health Organization, WHO Fact Sheet $N^{\circ} 348$, WHO, Geneva, Switzerland, 2016. 
[13] New York State Department of Health AIDS Institute, Preconception Care for HIV-Infected Women, New York State Department of Health AIDS Institute, New York, NY, USA, 2010.

[14] A. O. Onasoga, T. A. Osaji, O. A. Alade, and M. C. Egbuniwe, "Awareness and barriers to utilization of maternal health care services among reproductive women in Amassoma community, Bayelsa State," International Journal of Nursing and Midwifery, vol. 6, no. 1, pp. 10-15, January 2014.

[15] P. Batra, C. Higgins, and S. M. Chao, "Previous adverse infant outcomes as predictors of preconception care use: an analysis of the 2010 and 2012 Los Angeles mommy and baby (LAMB) surveys," Maternal and Child Health Journal, vol. 20, no. 6, pp. 1170-1177, 2016.

[16] N. N. Khan, J. Boyle, A. Y. Lang, and C. L. Harrison, "Preconception health attitudes and behaviours of women: a qualitative investigation," Nutrients, vol. 11, no. 7, p. 1490, 2019.

[17] Y. Ayalew, A. Mulat, M. Dile, and A. Simegn, "Women 's knowledge and associated factors in preconception care in adet, west gojjam, Northwest Ethiopia: a community based cross sectional study," Reproductive Health, vol. 14, no. 1, p. 15, 2017.

[18] Z. Jourabchi, S. Sharif, L. M. Sann, S. Asefzadeh, G. L. Khor, and S. H. S. Tajuddin, "Association between preconception care and birth outcomes," American Journal of Health Promotion, vol. 33, no. 3, pp. 363-371, 2018.

[19] S. F. Posner, K. Johnson, C. Parker, H. Atrash, and J. Biermann, "The national summit on preconception care: a summary of concepts and recommendations," Maternal and Child Health Journal, vol. 10, no. S1, pp. 199-207, 2006.

[20] Z. Y. Kassa, Z. Tenaw, A. Astatkie et al., "Mobile phone based strategies for preconception education in Rural Africa," Annals of Global Health, vol. 85, no. 1, 2019.

[21] A. L. V. Borges, O. A. d. Santos, N. d. C. Nascimento, C. B. d. N. Chofakian, and F. A. Gomes-Sponholz, "Preconception health behaviors associated with pregnancy planning status among Brazilian women," Revista da Escola de Enfermagem da USP, vol. 50, no. 2, pp. 208-216, 2016. 


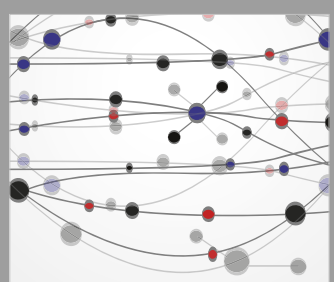

The Scientific World Journal
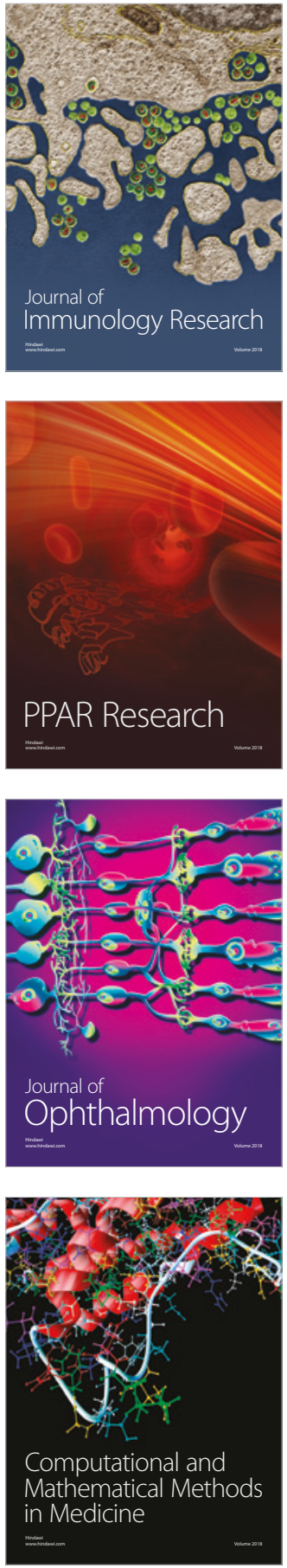

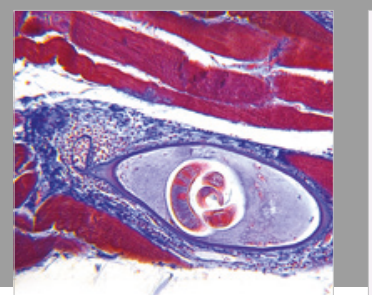

Gastroenterology Research and Practice

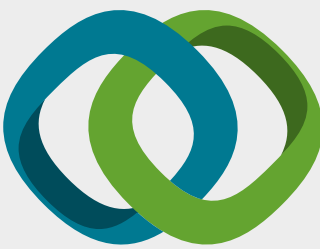

\section{Hindawi}

Submit your manuscripts at

www.hindawi.com
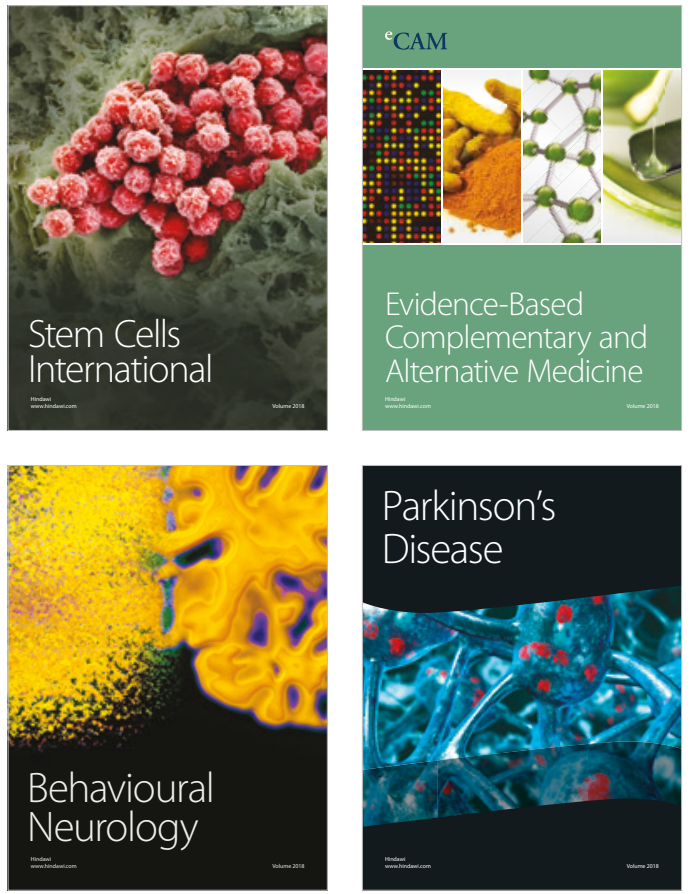

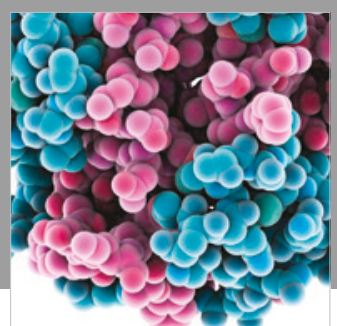

ournal of

Diabetes Research

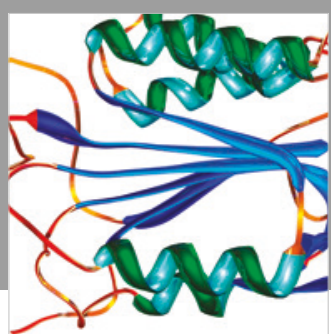

Disease Markers
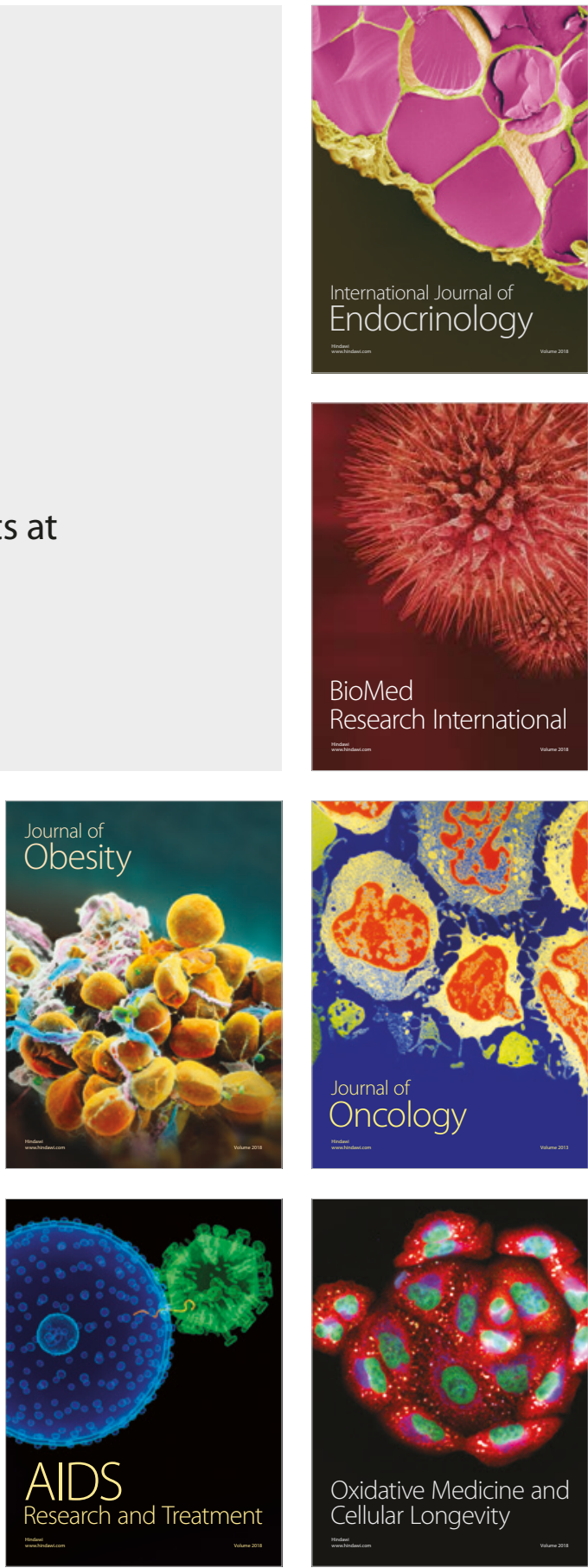